one percent (246) said they do not stop other anticoagulants (including aspirin, clopidogrel, heparins and novel oral antiocoagulants) prior to surgery.

Seventy-eight percent (236) of consultants cancelled based on blood glucose, with 40\% (121) stating above 25 $\mathrm{mmol} / \mathrm{L}$, and $32 \%(97)$ above $15 \mathrm{mmol} / \mathrm{L}$.

Of all the criteria, heart rate gave the most variable response, with only $40 \%$ (123) considering it as a reason for cancellation. There was a huge variety in the upper limit, and symptomatic tachycardia understandably was the most important reason $(14.8 \%, 45)$ rather than the rate.

Consultants across the UK show some consensus on when to cancel patients in relation to blood pressure, blood glucose, INR level and most do not routinely stop other forms of anticoagulation. However, there remains some variability in practice, which is understandable given the lack of specific guidance at present. Studies looking at the influence that these factors may have on cataract surgery are currently limited. A national audit looking at these parameters in relation to complications may be warranted. Our survey highlights a need for more exploration into the immediate pre-operative management of patients.

Funding This work has been presented previously at Royal College of Ophthalmologists Congress, Birmingham, UK, 2016.

\section{Compliance with ethical standards}

Conflict of interest The authors declare that they have no competing interests.

\section{References}

1. 2016-2017 National Prices and National Tariff Workbook. NHS England and Monitor. https://www.gov.uk/government/publications/nhs-national-tariff-payment-system-201617. Last accessed 05/01/2018

2. Cataract surgery guidelines October 2017. Royal College of Ophthalmologists/NICE. https://www.nice.org.uk/guidance/ng77. Last accessed 05/01/2018

3. Local Anaesthesia for Ophthalmic Surgery. Joint guidelines from the Royal College of Anaesthetics and the Royal College of Ophthalmologists. February 2012

\title{
A model of clinical practice: a randomised clinical study evaluating patient satisfaction of nurse-led vs consultant-led intravitreal injection
}

\author{
Ryian Mohamed (i) ${ }^{1} \cdot$ Dhannie Ramcharan ${ }^{2} \cdot$ Sinduya Srikaran $^{2} \cdot$ Evelyn Mensch $^{2}$
}

Received: 26 November 2017 / Accepted: 1 December 2017 / Published online: 5 February 2018

(c) The Royal College of Ophthalmologists 2018

Intravitreal injection treatment (IVT) is the most commonly performed ophthalmic procedure [1]. Evidence now shows that nurse-led IVT achieves comparable safety, visual outcomes and complication rates as consultant-lead care [1-3]. However, patient satisfaction of IVT by non-ophthalmologists, an increasingly common practice [4], has been poorly studied. This is concerning, given the importance of patient

Ryian Mohamed

m0601207@gmail.com

1 General Medicine, Luton and Dunstable Hospital, Luton, UK

2 Department of Ophthalmology, Central Middlesex Hospital, London, UK satisfaction in assessing the quality of medical care and determining levels of treatment viability, therapeutic compliance and malpractice litigation. Our aim was to compare patient satisfaction of nurse-led vs consultant-led IVT.

Patients attending the macular treatment clinic at Central Middlesex Hospital were invited to take part in the study. A total of 61 patients agreed to participate and were subsequently consented and randomised to receive IVT treatment by either the trained clinical nurse $(n=34)$ or by the consultant $(n=27)$ - the 'gold standard'. A modified, validated patient questionnaire (PSQ-18), see Fig. 1, was used to determine six aspects of patient satisfaction. Responses to each item were given a 5-point scale ranging from strongly agree (5 points) to strongly disagree ( 0 points). A painscale, 


\begin{tabular}{|l|c|c|c|c|c|}
\hline & $\begin{array}{l}\text { Strongly } \\
\text { disagree }\end{array}$ & Disagree & Uncertain & Agree & $\begin{array}{c}\text { Strongly } \\
\text { agree }\end{array}$ \\
\hline $\begin{array}{l}\text { When I came for my eye injection the } \\
\text { care I received was very good }\end{array}$ & 1 & 2 & 3 & 4 & 5 \\
\hline $\begin{array}{l}\text { I am dissatisfied with some things } \\
\text { about the care I received today }\end{array}$ & 1 & 2 & 3 & 4 & 5 \\
\hline $\begin{array}{l}\text { I felt in safe hands when the } \\
\text { doctor/nurse gave the injection }\end{array}$ & 1 & 2 & 3 & 4 & 5 \\
\hline $\begin{array}{l}\text { When I came for my eye injection the } \\
\text { doctor/nurse was careful to check } \\
\text { everything when treating me }\end{array}$ & 1 & 2 & 3 & 4 & 5 \\
\hline $\begin{array}{l}\text { I have some doubts about the ability of } \\
\text { the doctor/nurse who administrated my } \\
\text { injection }\end{array}$ & 1 & 2 & 3 & 4 & 5 \\
\hline $\begin{array}{l}\text { The doctor/nurse made sure I was } \\
\text { comfortable and pain free during my } \\
\text { injection }\end{array}$ & 1 & 2 & 3 & 4 & 5 \\
\hline $\begin{array}{l}\text { The doctor/nurse treated me in a very } \\
\text { friendly and courteous manner }\end{array}$ & 1 & 2 & 3 & 4 & 5 \\
\hline $\begin{array}{l}\text { My eye injection procedure was } \\
\text { explained to me clearly by the } \\
\text { doctor/nurse }\end{array}$ & 1 & 2 & 3 & 4 & 5 \\
\hline $\begin{array}{l}\text { The doctor/nurse hurried too much } \\
\text { when they treated me }\end{array}$ & 1 & 2 & 3 & 4 & 5 \\
\hline $\begin{array}{l}\text { I was happy with the time taken for } \\
\text { my hospital visit today }\end{array}$ & 1 & 2 & 3 & 4 & 5 \\
\hline $\begin{array}{l}\text { The doctor/nurse appeared } \\
\text { knowledgeable and competent }\end{array}$ & 1 & 2 & 3 & 4 & 5 \\
\hline
\end{tabular}

Fig. 1 Modified PSQ-18 patient questionnaire. The questions below are about how you feel about the care you receive when you have your eye injection. Please read each one carefully. How strongly do you AGREE or DISAGREE with each of the following statements? (Circle one number on each line)

ranging from 0 (no pain) to 10 (maximum pain) points, was also used to determine comfort levels during treatment. $\chi^{2}$ test of independence was performed to evaluate differences between the two groups.

We found that most patients, $85 \%$, had no preference for receiving nurse-led or consultant-led IVT, with only $15 \%$ of patients objecting to nurse-led IVT. The patients surveyed heralded from a diverse range of backgrounds: 43\% Caucasian, 39\% Asian, 13\% African and 5\% other. All the patients had attended the macular treatment clinic at least once previously, with over half (57\%) attending for more than 1 year, and $36 \%$ attending for multiple visits.

The responses of the patient survey $(n=61)$ showed no significant difference between the nurse and consultant across all six domains of patient satisfaction when receiving IVT. This included: general satisfaction (4.71 vs $4.65, p=0.90)$, technical quality (4.90 vs $4.97, p=0.30$ ), interpersonal manner (4.97 vs $5.00, p=0.60$ ), information and communication (4.91 vs 4.93, $p=0.70$ ), time spent with the consultant or nurse (4.09 vs 4.28, $p=0.70$ ) and staff competence (4.97 vs $5.00, p=0.10$ ). There was also no significant difference in patient pain scores between nurse and consultant IVT ( 0.6 vs $0.4, p=$ $0.40)$. Please see Table 1 for a results summary. No complications or complaints were recorded during the study period.

In conclusion, patient satisfaction of nurse- vs consultant-led IVT is equivalent. Nurse injectors are key
Table 1 Mean patient satisfaction scores $(n=61)$

\begin{tabular}{llll}
\hline & $\begin{array}{l}\text { Mean score } \\
\text { doctor }(n=27)\end{array}$ & $\begin{array}{l}\text { Mean score } \\
\text { nurse }(n=34)\end{array}$ & $p$ value \\
\hline $\begin{array}{l}\text { Modified PSQ-18 scale } \\
\text { (0-5 points) }\end{array}$ & & & \\
$\quad$ General satisfaction & 4.65 & 4.71 & 0.90 \\
$\quad$ Technical quality & 4.97 & 4.90 & 0.30 \\
$\quad$ Interpersonal manner & 5.00 & 4.97 & 0.60 \\
$\quad$ Information/ & 4.93 & 4.91 & 0.70 \\
$\begin{array}{c}\text { communication } \\
\text { Time spent with }\end{array}$ & 4.28 & 4.09 & 0.70 \\
doctor/nurse & & 4.97 & 0.10 \\
$\quad$ Staff competence & 5.00 & & 0.40 \\
Painscale (1-10 points) & & 0.6 & \\
$\quad$ Pain score & 0.4 & & \\
\hline
\end{tabular}

players in providing IVT services and ultimately preventing visual loss and blindness. However, The Royal College of Ophthalmologists (RCO) advice remains that IVT: 'should be provided by an ophthalmic surgeon experienced with this procedure and with the management of IVT related complications or by a trainee under supervision of such an ophthalmologist' [5]. The Royal College of Ophthalmologists guidelines should be updated to reflect the value of advanced nurse practitioners and specialist nurses in also delivering a golden-standard of care.

\section{Compliance with ethical standards}

Conflict of interest The authors declare that they have no competing interests.

\section{References}

1. Gregg E. Nurse-led ranibizumab intravitreal injections in wet agerelated macular degeneration: a literature review. Nurs Stand. 2017;31:44-52.

2. Michelotti M, Abugreen S, Kelly S, Morarji J, Myerscough D, Boddie T, Haughton A, Nixon N, Mason B, Sioras E. Transformational change: a nurses substituting for ophthalmologists for intravitreal injections-a quality-improvement report. Clin Opthalmol. 2014;8:755-61.

3. DaCosta J, Hamilton R, Nago J, Mapani A, Kennedy E, Luckett t, Pavesio C, Flanagan D. Implementation of a nurse-delivered intravitreal injection service. Eye. 2014;28:734-40.

4. Amoaku W. The Royal College of Ophthalmologists. Maximising capacity in AMD services; 2013.

5. Andrew BA, Pearce I, Amoaku W. The Royal College of Ophthalmologists. Guidelines for intravitreal injections procedure; 2009. 